\title{
An Overview of Thermal Behavior of Polymers: Lead Acid Battery Applications
}

\author{
Shyamsundar Reddy Peram, Madhava Rao Byraboina, Narendran Dama, \\ Suryanarayana Murthy Kurivella, and Jagadish Mandava
}

\begin{abstract}
Thermal analysis is the analysis of a change in a property of a material, which is related to the temperature difference. Polymer samples are typically in solid form and undergo various thermal transitions upon heating, including melting, phase transition, sublimation, and decomposition. The purpose of this study is to demonstrate how thermal techniques such as DSC and TGA may be used to evaluate polymer thermal stability through the examination of polymer characteristics such as glass transition temperatures, melting points, and mass changes. Different polymers have been investigated and used in lead-acid batteries for various applications based on their mechanical and thermal characteristics. Few lead-acid batteryrelated polymers like Polypropylene (PP), Polyethylene (PE) Separator, Polyethylene Terephthalate (PET), Polyvinyl Chloride (PVC) and Acrylonitrile butadiene styrene (ABS) were studied and explained.
\end{abstract}

Keywords - ABS, Differential Scanning Calorimetry (DSC), PET, PPCP, PVC, Thermogravimetry Analysis (TGA), etc.

\section{INTRODUCTION}

Polymers are either inorganic or organic macromolecules and have a higher molecular weight, which are composed of longer molecule chains that are either entirely disordered (amorphous in nature) or partially disordered (semicrystalline in nature). As the temperature increases, the ordered polymers will starts melting, whereas the amorphous polymers will exhibit only glass transition temperatures [1].

Depending on the nature of the bonds between the polymer chains, polymers are classified into three groups: thermoplastics, thermosets, and elastomers. In thermoplastics, there will be no covalent bonding between the polymer's chains. These polymers are either ordered or disordered in nature. The chemical nature of thermoplastics won't be impacted with repeated heating's and cooling's, and the process is reversible as long as there is no thermal damage to the material during heating. Examples of Thermoplastics are Polyethylene and Polypropylene etc.

In thermosets, the polymer chains undergo dense crosslinking during heating. When fully cured, these polymers are neither deformable nor melt-able. Thermosets have only glass transition temperatures and decompose at higher temperatures. Examples of Thermosets are Epoxy Resins and Polyurethane etc.

Submitted on December 20, 2021

Published on January 10, 2022.

Shyamsundar Reddy Peram, Amara Raja Batteries Limited, Tirupathi, A.P, India

(e-mail: shyamsundar9888@gmail.com)

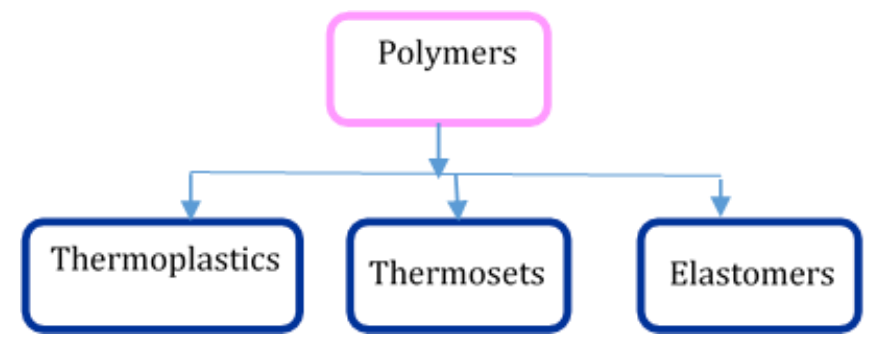

Fig. 1. Classification of Polymers.

In elastomers, the polymers chains have low density crosslinking. At low temperatures, they will lose elasticity and freezes as hard as glass. Likewise, thermosets, elastomers exhibit only glass transition temperatures and do not melt. Examples of Elastomers are Natural Rubber and Ethylene Propylene Diene Rubber etc.

The glass transition occurs when amorphous polymers or amorphous domains of semi-crystalline thermoplastics change from a glassy or energy-elastic state to a rubbery or entropy-elastic state. The temperature at which the glass transition occurs is dependent on the processing induced morphology (e.g., orientation, crystallization, cross-linking, internal stress). Amorphous thermoplastics undergo major, usually step-like changes in their properties during the glass transition. Semi-crystalline thermoplastics are less affected by these changes since the crystalline phase is still unmelted and crystallinity, which is the proportion of the crystalline phase, plays a role. The crystallinity of a polymer is influenced by its chemical structure, cooling conditions during processing, and any thermal post-treatment. The more crystalline the molded part, the more rigid and robust it is and the more brittle [2], [3].

Thermal analysis is one of the oldest analytical techniques used for determining the material properties and phase transitions and characterizing polymers. Identification of materials, especially those used in the field of polymers, is of critical importance, especially when it comes to raw material quality control and failure analysis. Classical thermal analysis techniques such as differential scanning calorimetry (DSC) and thermogravimetric analysis (TGA) are also commonly utilized to analyze polymers. Energy effects observed in the DSC signal, e.g., the glass transition, crystallization and melting, and the pyrolytic decomposition and the combustion of the polymer samples can be studied using TGA [4].

Madhava Rao Byraboina, Amara Raja Batteries Limited, Tirupathi, A.P, India.

Narendran Dama, Amara Raja Batteries Limited, Tirupathi, A.P, India.

Suryanarayana Murthy Kurivella, Amara Raja Batteries Limited, Tirupathi, A.P, India.

Jagadish Mandava, Amara Raja Batteries Limited, Tirupathi, A.P, India. 
Simultaneous thermal analysis (STA) refers to applying two or more techniques to the same sample at the same time, which signifies the simultaneous measurement of DSC and TGA. The STA technique has essential advantages over simply combining measurements performed in different instruments on different samples of the same type. In addition to the higher efficiency, we can directly compare the signals from the DSC and TGA measurements without having to discuss possible differences in sample composition, sample preparations, or measurement conditions.

DSC, one of the most effective analytical methods, is used to investigate material thermal characteristics and phase changes. It measures the heat flow difference between the reference crucible and sample during the heating or cooling conditions in a specified atmosphere. The critical parameters like Glass transition temperatures, Melting temperatures, Heat of reaction (Transition / Reaction Enthalpy), Specific Heat Capacity, Fraction of crystallinity of a polymer etc., can be studied through DSC [5], [6].

\section{Basic Equations of DSC \& TGA:}

Enthalpy:

$$
\mathrm{d} Q \mid \mathrm{d} t=m * C_{P} *[\mathrm{~d} T / \mathrm{d} t]
$$

Mass Loss / Gain:

$$
\alpha=\frac{m_{o}-m_{i}}{m_{0}}
$$

where, $\mathrm{m}=$ mass of sample, $\mathrm{g}$;

$\mathrm{T}=$ Temperature, $\mathrm{K}$;

$\mathrm{t}=$ Time, $\min$;

$\mathrm{C}_{\mathrm{p}}=$ Thermal capacity, $\mathrm{J} /(\mathrm{g} \times \mathrm{K})$;

$\mathrm{Q}=$ Heat of the process (reaction);

$\alpha=$ Mass loss/ Gain.

TGA measures the mass change and transformation energetics of a sample with respect to time or temperature in an inert or reactive atmosphere. Key studies like compositional analysis, thermal and oxidative stabilities, decomposition analysis of materials can be studied through TGA. This technique can be used to estimate the mass changes happened during oxidation, dehydration, adsorption, desorption, and decomposition processes.

\section{MATERIALS \& EXPERIMENTATION}

Polymers have wide applications in different fields due to their versatile and unique physical, chemical, and thermal properties. Materials like PPCP, PE Separator, PET, PVC, and ABS have been used in Lead Acid battery for various applications and were described in detail [7], [8].

\section{A. Polypropylene Copolymer}

Polypropylene is a thermoplastic polymer in the polyolefin family. Polypropylene is an economical polymer with unique physical, mechanical, thermal, and electrical properties not found in any other thermoplastic. It has a lower impact strength but a higher operating temperature and tensile strength than low or high-density polyethene Polypropylene provides excellent chemical resistance to organic solvents, corrosive environments, and electrolytic attacks. In general, it is light in weight, strain resistant and has a low moisture absorption rate. It is available in two basic types as either homopolymer or copolymer material. Although similar in many characteristics, each type exhibits distinct differences in both appearance and performance.

Polypropylene Homopolymer (PPHP) is the most widely utilized. It offers a high strength-to-weight ratio and is stiffer and stronger than copolymer; combined with good chemical resistance and weldability, this material can be used in many corrosion-resistant structures.

Polypropylene Copolymer (PPCP) is slightly softer and more malleable than the homopolymer but has higher impact strength and durability. It is also more resistant to stress cracks and is tougher at lower temperatures. PPCP is very versatile and low-cost material. Its lower rigidity is ideal for use in automotive tanks to prevent cracking from road vibration and can also be used for applications that require good chemical resistance

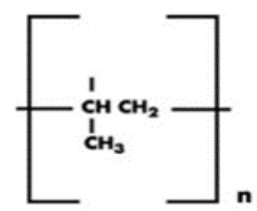

Fig. 2. Chemical Structure of PP

The polypropylene copolymer has the ideal properties that make it the best material for a battery cover and container. Polypropylene containers moulded with thin partitions and thin walls which increases the acid volume thereby makes possible higher capacities for given sizes or new compact battery designs [9].

\section{B. Polyethylene}

Polyethylene (PE) is a semi-crystalline thermoplastic polymer and belongs to the Polyolefin family, synthesized from ethylene's polymerization. Due to its molecular weight and density, there are different grades of PE like Low density (LDPE), Linear Low density (LLDPE), High density (HDPE) and Ultra High Molecular Weight (UHMWPE).

LDPE is a low density polymer which consists of extensively branched polymer chains. LLDPE is conventionally different from LDPE, which has only short branching and significantly different rheological properties. HDPE has relatively few branching structures and hence, have a high density. Polyethylene of ultra-high molecular weight (UHMWPE) has very long molecular chains with a very high molecular weight.

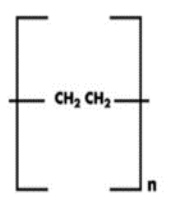

Fig. 3. Chemical Structure of PE.

In general, Polyethylene exhibits high chemical resistance, better stability, very low water absorption and good electrical resistance. Polyethylene based separators (PE Separators) are broadly used in lead acid batteries as battery separators to avoid the contact between Positive and Negative electrodes. These are composed of Polyethylene, Silica, Oil, and other 
pigments for the required properties. The separator should be porous and resistant to acid [10].

\section{PET}

Polyethylene terephthalate (PET) is a semi-crystalline polymer with a hydrophobic characteristic. The basic building blocks of PET are ethylene glycol and terephthalic acid, which are combined to form a polymer chain. Its glass transition temperatures range from 70 to $85^{\circ} \mathrm{C}$, and melting temperatures range from 245 to $260{ }^{\circ} \mathrm{C}$.

PET has good abrasion resistance, good acid resistance, high stability, and stiffness. For beverages bottles and packing application, PET in amorphous nature will be used due to its high transparency and breaking resistance.

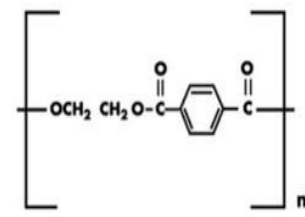

Fig.4. Chemical Structure of PET.

Polyester, the world's synthetic fiber is synthesizing from PET, when can be used for fiber or fabric applications. PET is electrically and chemically stable with these advantages; the Polyester fibers are widely used as binders for the lead acid active materials, which improves the adhesion of the electrode's active material [11].

\section{D. $P V C$}

Polyvinyl Chloride (PVC) is an amorphous thermoplastic polymer and the most widely produced synthetic plastic polymer due to its versatile nature. It does not have true melting temperatures and has only a glass transition temperature. PVC is available in two grades based on with and without plasticizer, i.e., namely, Plasticized PVC and Unplasticized PVC.

PVC generally exhibits good chemical resistance, good electrical insulation and low water absorption. It has a wide application in the fields of electrical cable construction for insulation, sheathing and bedding. Synthetic PVC is resistant to various chemicals, including oils, acids, and alkalis, and is tough, durable, and resistant to abrasion.

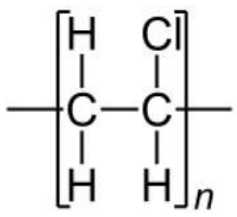

Fig. 5. Chemical Structure of PVC. temperature is approximately 95 to $125^{\circ} \mathrm{C}$.

The mechanical and chemical properties of ABS depend on the individual components proportion and the method of manufacturing. ABS is a heat-resistant and low water absorption polymer with good mechanical properties like stiffness and impact strength. It remains hard, rigid, and tough even at low temperatures. It is also available in different grades like fire-resistant, heat-resistant, etc.

ABS material is suitable for containers and covers material for battery application with these versatile properties. The ABS container and covers either coupled with heat sealing or hot melt adhesives [13].

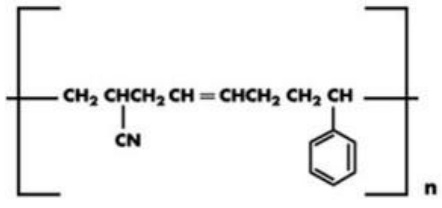

Fig. 6. Chemical Structure of ABS

\section{F. Experimentation}

The DSC and TGA analysis measurements were executed using the NETZSCH DSC 214 Polyma and the NETZSCH STA 449 F3 Jupiter ${ }^{\circledR}$ and pure nitrogen as the purge gas. For thermal analysis, the selection of temperature range plays a critical role and polymer samples of masses in the range of 8 to $12 \mathrm{mg}$ were prepared with the help of Sample cutter for a better thermal contact between crucible and sample and sample analyzed conditions were tabulated in Table I.

For DSC analysis, the polymer samples were heated from an initial temperature of $25{ }^{\circ} \mathrm{C}$ to above its melting temperature to erase the previous thermal history with a heating rate of $10 \mathrm{~K} / \mathrm{min}$ and kept isothermal for $5 \mathrm{mins}$, then cooled down with a rate of $10 \mathrm{~K} / \mathrm{min}$ to initial temperature of $25{ }^{\circ} \mathrm{C}$ and then heated again with a heating rate of $10 \mathrm{~K} / \mathrm{min}$ to above the melting temperature. The first heating will assess the material properties in moulded or previous processed conditions whereas the second heating will assess the inherent material properties. For better understanding, the second heating curve results were taken into consideration.

For TGA analysis, the polymeric samples were heated from room temperatures to $600{ }^{\circ} \mathrm{C}$ with a heating rate of $10 \mathrm{~K} / \mathrm{min}$, in which the samples were kept isothermal at room temperatures for $5 \mathrm{mins}$ and then heated to $600{ }^{\circ} \mathrm{C}$. In this paper, TGA analysis was performed, and the results were shown in two ways i.e., TG curve - mass loss curve w.r.t temperature and DTG curve - derivative mass loss curve w.r.t temperatures.

TABLE I. SAMPLE ANALYSIS CONDITIONS

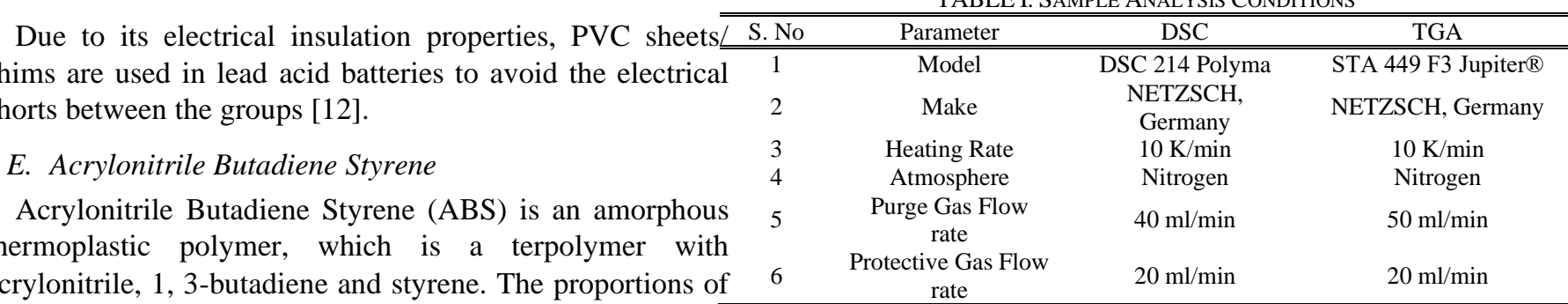
individual components may vary from 15 to $35 \%$ acrylonitrile, 5 to $30 \%$ butadiene and 40 to $60 \%$ styrene. It does not have a true melting point, and its glass transition 


\section{RESULTS \& DISCUSSIONS}

Under applied heating conditions, the polymeric sample will undergo changes in physical and chemical properties, which affects the chemical composition of the polymer and the physical parameters like the color of polymer, chain length, molecular weight and its distribution, crystallinity, chain flexibility, cross linking and branching [14]. The cumulative outcome of DSC analysis tabulated as given in Table II \& Table III.

\section{A. $P P C P$}

From the DSC analysis as shown in Fig. 7(a), observed that the cold crystallization at $119.6^{\circ} \mathrm{C}$, and melting at $167.6^{\circ} \mathrm{C}$. Under an inert nitrogen atmosphere, as shown in Fig. 7(b), the TGA of PPCP shows a single step of thermal degradation around $446.6^{\circ} \mathrm{C}$ which ranges from $350{ }^{\circ} \mathrm{C}$ to $500{ }^{\circ} \mathrm{C}$. During the heating process, pyrolysis takes place due to similar chemical bonds which results in major mass loss. Thermal degradation of PPCP causes chain breaking and then reduced chain length reduces the molecular weight, which influences the mechanical properties leading to highly reduced ductility and embrittlement [15]-[17].

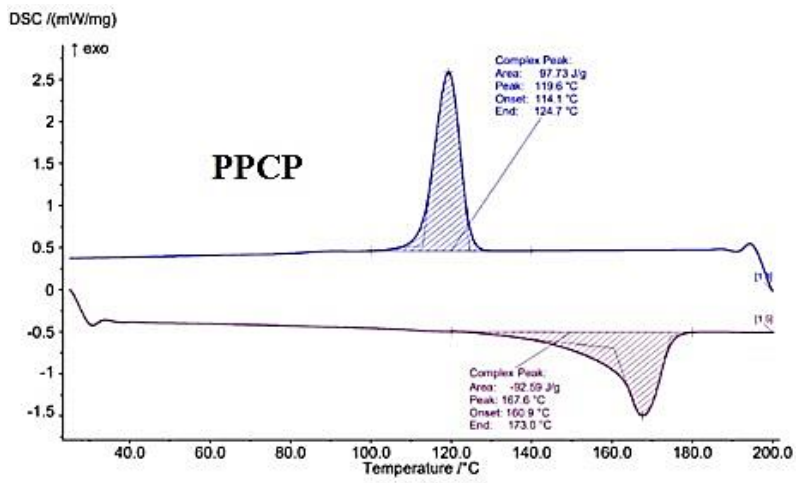

Fig. 7(a). DSC Analysis of PPCP.

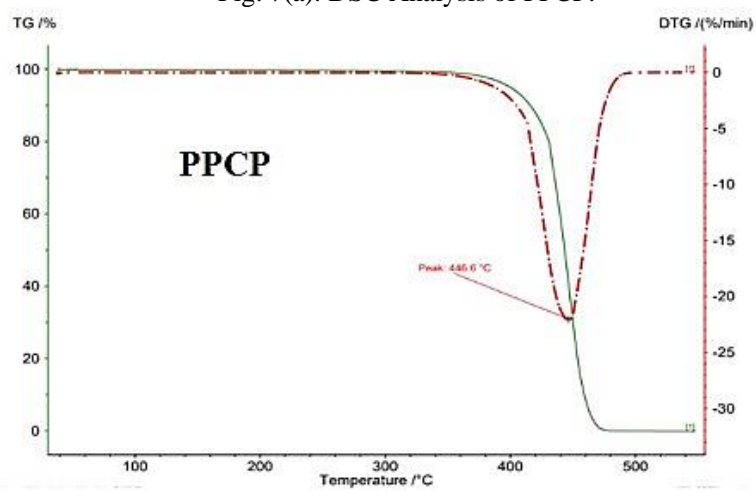

Fig. 7(b). TGA/DTG Analysis of PPCP.

\section{B. PE Separator}

Under inert nitrogen atmosphere, TGA of PE Separator shows a multi-step of thermal degradation with different mass losses due to other materials like oil and silica. From the DSC analysis as shown in Fig. 8(a), observed that the cold crystallization was at $107.4{ }^{\circ} \mathrm{C}$, and melting at $127.7^{\circ} \mathrm{C}$. The decomposition temperature of $\mathrm{PE}$ is around $473.1{ }^{\circ} \mathrm{C}$ which ranges from $400^{\circ} \mathrm{C}$ to $500{ }^{\circ} \mathrm{C}$, as shown in the Fig. 8(b) DTG curve [16]-[19].

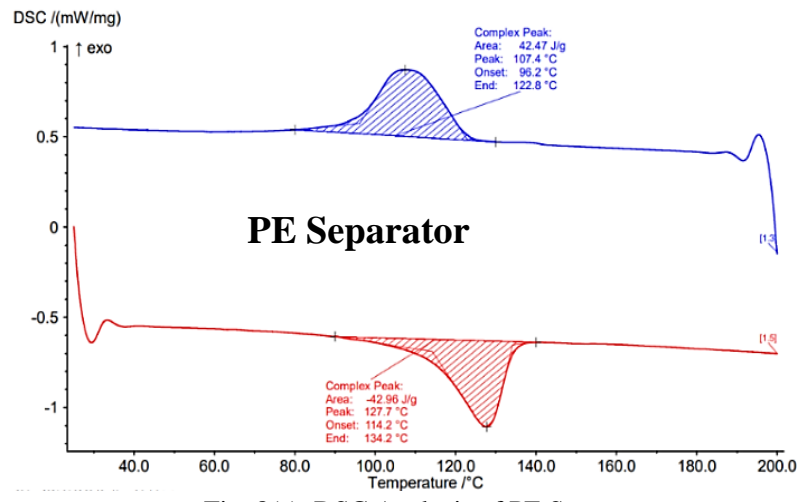

Fig. 8(a). DSC Analysis of PE Separator.

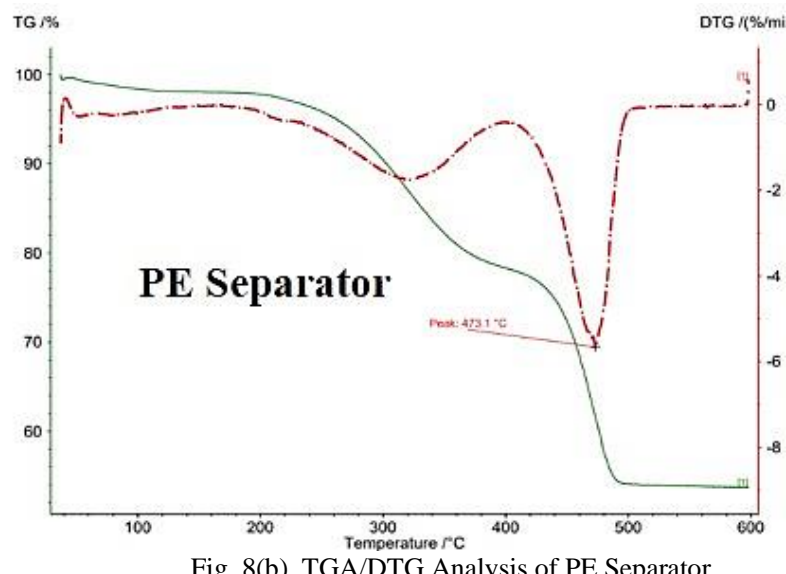

\section{PET}

From Fig. 9(a) \& Fig. 9(b) i.e., the DSC and TGA curves, it is evident that PET is semi-crystalline in nature and has the glass transition temperature. TGA of PET shows a single step thermal degradation, in which the observed decomposition temperature of PET is around $434.3^{\circ} \mathrm{C}$ which ranges from $350{ }^{\circ} \mathrm{C}$ to $500{ }^{\circ} \mathrm{C}$, as shown in the DTG curve. From the DSC analysis, observed that the cold crystallization was at 177.3 ${ }^{\circ} \mathrm{C}$, and melting at $254.9^{\circ} \mathrm{C}$. This maximum mass loss is due to thermal degradation of the polymer backbone, i.e., chain scission of the ester bonds. [19]-[21].

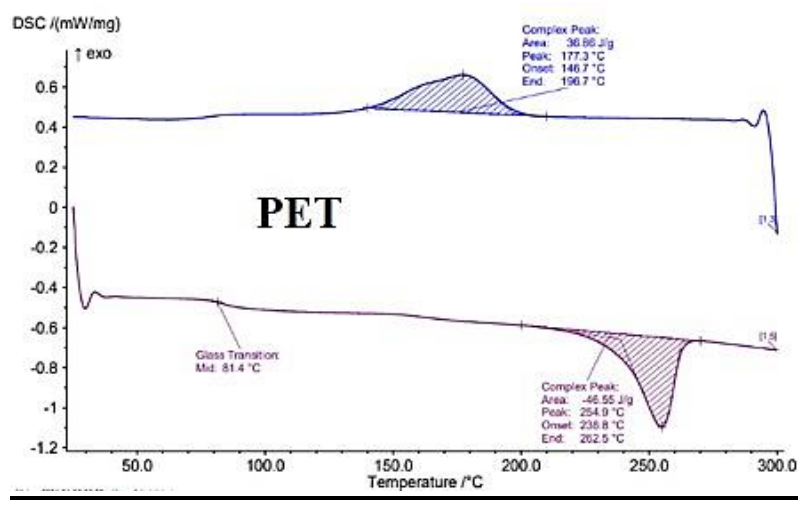

Fig. 9(a). DSC Analysis of PET. 


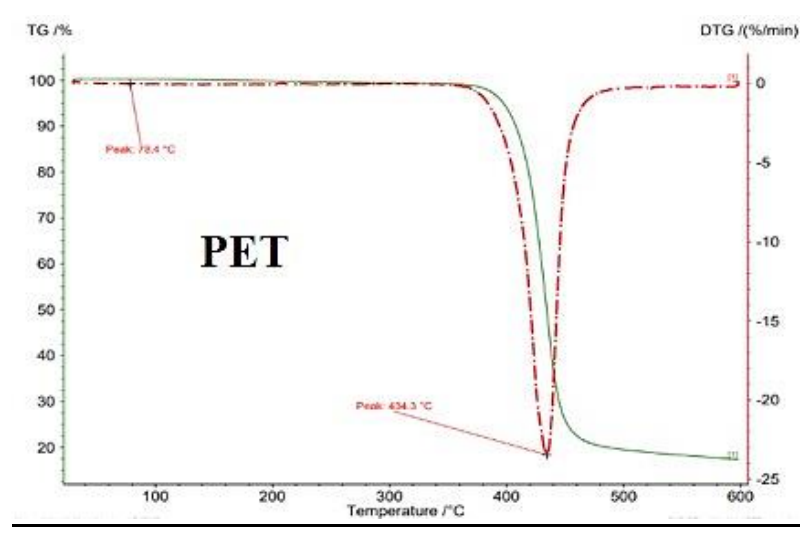

Fig. 9(b). TGA/DTG Analysis of PET.

TABLE II:"As RECEIVED" DSC CHARACTERIZATION OF SAMPLES

\begin{tabular}{|c|c|c|c|c|c|c|c|}
\hline $\begin{array}{c}\text { S. } \\
\text { No }\end{array}$ & Parameter & UOM & PPCP & PE & PET & PVC & ABS \\
\hline 1 & $\begin{array}{l}\text { Glass transition } \\
\text { temperature-Mid } \\
\text { Melting }\end{array}$ & ${ }^{\circ} \mathrm{C}$ & & & 81.4 & 63.6 & 104.8 \\
\hline 2 & $\begin{array}{c}\text { Extrapolated Onset } \\
\text { Temperature }\end{array}$ & ${ }^{\circ} \mathrm{C}$ & 160.9 & 114.2 & 238.8 & & \\
\hline 3 & $\begin{array}{c}\text { Melt Peak } \\
\text { Temperature } \\
\text { Melting }\end{array}$ & ${ }^{\circ} \mathrm{C}$ & 167.6 & 127.7 & 254.9 & & \\
\hline 4 & $\begin{array}{l}\text { Extrapolated End } \\
\text { Temperature }\end{array}$ & ${ }^{\circ} \mathrm{C}$ & 173 & 134.2 & 262.5 & & \\
\hline 5 & $\begin{array}{c}\text { Melting } \\
\text { Enthalpy/Area }\end{array}$ & $\mathrm{J} / \mathrm{g}$ & $\begin{array}{c}- \\
92.59\end{array}$ & $\begin{array}{c}- \\
42.96\end{array}$ & $4{ }^{-}$ & & \\
\hline
\end{tabular}

TABLE III: DSC CHARACTERIZATION OF SAMPLES AFTER A COMMON THERMAL HISTORY

\begin{tabular}{|c|c|c|c|c|c|c|c|}
\hline $\begin{array}{l}\text { S. } \\
\text { No }\end{array}$ & Parameter & UOM & PPCP & PE & PET & $\begin{array}{l}\mathrm{P} \\
\mathrm{V} \\
\mathrm{C} \\
\end{array}$ & $\begin{array}{l}\text { A } \\
\text { B } \\
\text { S } \\
\end{array}$ \\
\hline 1 & $\begin{array}{l}\text { Crystallization } \\
\text { Extrapolated } \\
\text { Onset } \\
\text { Temperature }\end{array}$ & ${ }^{\circ} \mathrm{C}$ & 114.1 & 96.2 & 146.7 & & \\
\hline 2 & $\begin{array}{l}\text { Crystallization } \\
\text { Peak } \\
\text { Temperature }\end{array}$ & ${ }^{\circ} \mathrm{C}$ & 119.6 & 107.4 & 177.3 & & \\
\hline 3 & $\begin{array}{l}\text { Crystallization } \\
\text { Extrapolated End } \\
\text { Temperature }\end{array}$ & ${ }^{\circ} \mathrm{C}$ & 124.7 & 122.8 & 196.7 & & \\
\hline 4 & $\begin{array}{l}\text { Crystallization } \\
\text { Enthalpy/Area }\end{array}$ & $\mathrm{J} / \mathrm{g}$ & 97.73 & 42.47 & 36.86 & & \\
\hline
\end{tabular}

\section{D. $P V C$}

PVC has a glass transition temperature of $63.6{ }^{\circ} \mathrm{C}$, as shown in the Fig. 10(a) DSC curve. It has a two-step thermal degradation process with two decomposition temperatures of $297.3{ }^{\circ} \mathrm{C} \& 438.2{ }^{\circ} \mathrm{C}$, as shown in the Fig. 10(b) DTG curve. In general, Dehydrochlorination of PVC is a free radical reaction. The first mass loss step ranging from $230-360{ }^{\circ} \mathrm{C}$, is considered the most important step because in this stage $\mathrm{C}$ $\mathrm{Cl}$ bond in the PVC, which has less energy than the $\mathrm{C}-\mathrm{C}$ bond, dissociates first, resulting in the volatilization of hydrogen chloride molecule. The next mass loss step ranging from $360-500{ }^{\circ} \mathrm{C}$, corresponds to the thermal cracking of the carbon chain leading to the formation of alkane and alkene compounds [19], [22], [23].
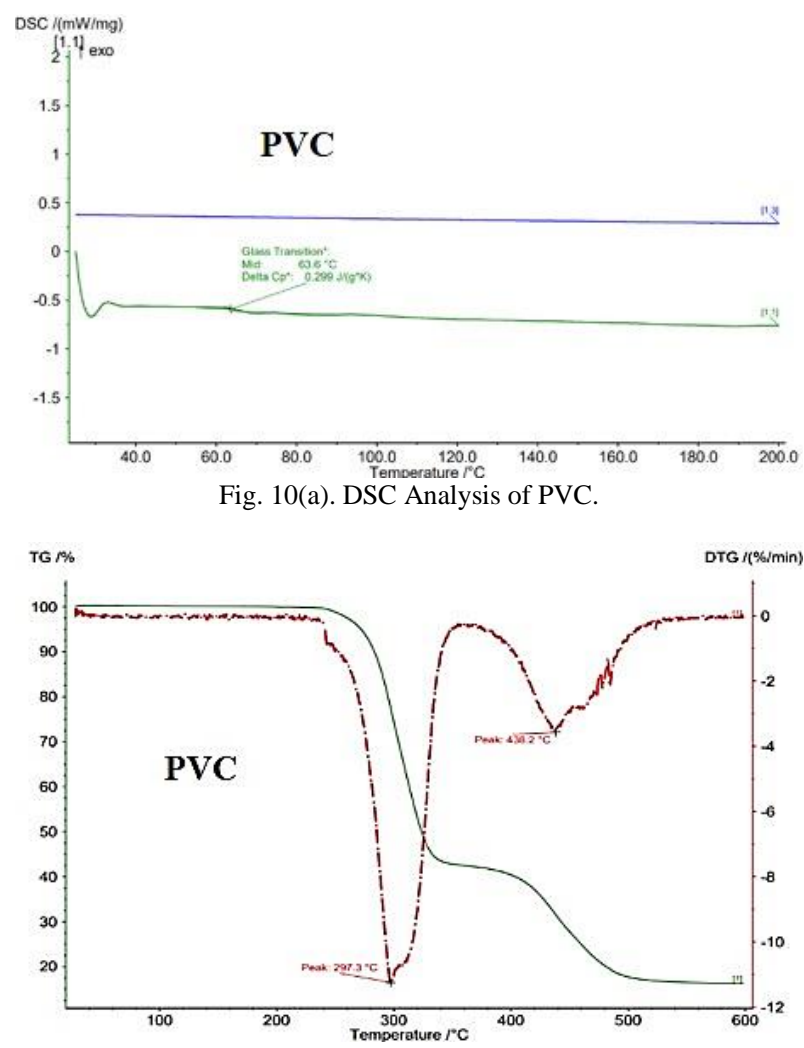

Fig. 10(b). TGA/DTG Analysis of PVC.

\section{E. $A B S$}

Fig. 11(a) \& Fig. 11(b) shows the DSC and TGA analysis results for ABS polymer at a constant heating rate. As earlier said, ABS is an amorphous polymer that does 'not have a true melting point and observed the glass transition temperature of $104.8{ }^{\circ} \mathrm{C}$. ABS decomposes in a single step thermal reaction mechanism and major mass loss ranging from 340 ${ }^{\circ} \mathrm{C}$ to $510{ }^{\circ} \mathrm{C}$ and decomposes at $420.4{ }^{\circ} \mathrm{C}$ as per the DTG curve. ABS is thermo-oxidative degradation, which begins at $340{ }^{\circ} \mathrm{C}$ with the evolution of butadiene monomer. With increasing temperatures, styrene becomes more important, and at $420.4{ }^{\circ} \mathrm{C}$ the intensities of the $\mathrm{C}-\mathrm{H}$ bonds in butadiene and styrene will become equal. Aliphatic and aromatic $\mathrm{C}-\mathrm{H}$ bonds will be broken with increased temperatures. The evolution of acrylonitrile begins at about $400{ }^{\circ} \mathrm{C}$ and ceases by $510{ }^{\circ} \mathrm{C}$ [24], [25].

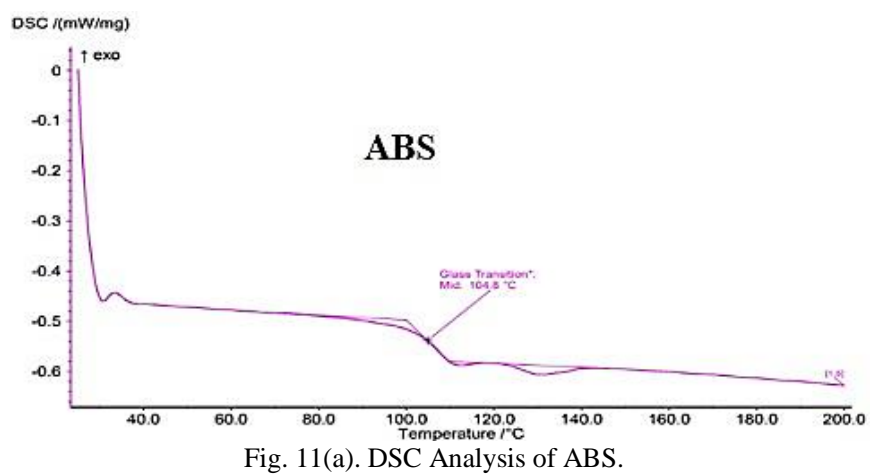




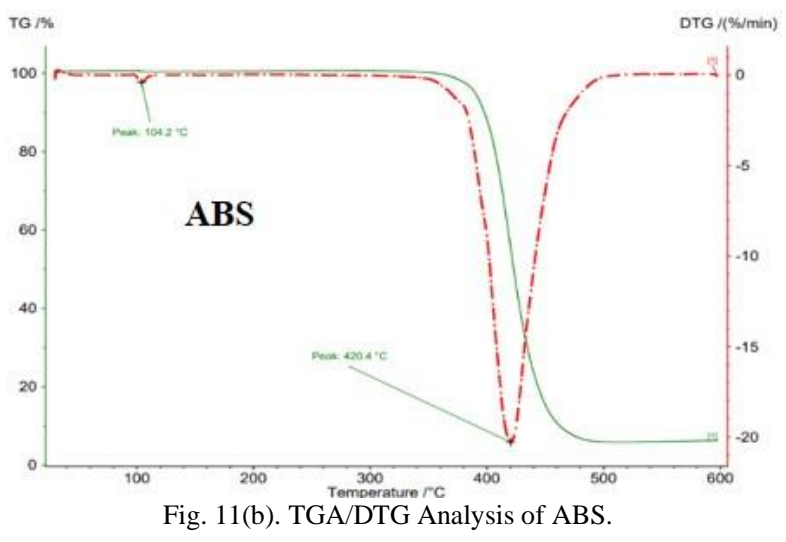

\section{CONCLUSION}

In Summary, DSC and TGA are efficient analytical tools to assess the thermal behavior of basic raw materials, subproducts, and active materials for lead-acid batteries. These thermal methods provide new information about the changes in phase composition and physical properties of the active materials and other Raw materials. This analytical data can throw light on the processes during battery production and operation, which will be more helpful in the decision making of raw material selection, process parameters optimization, trouble shooting, grade variations, new material validations, new polymer formulations and vendor validations etc. Some of the useful areas in which these techniques play a predominant role in a better poly grade selection for battery container and cover, identification of root causes for heat seal rejections, polymer cover variations, polymer based separator quantification and polymer crystallinity etc.

\section{ACKNOWLEDGEMENT}

The authors would like to express their gratitude to the Management of R\&D, Technology Center, Amara Raja Batteries Limited: Tirupati, for their continuous support and encouragement.

\section{REFERENCES}

[1] D'Amico Teresa, Donahue Craig J, Rais Elizabeth A. Thermal Analysis of Plastics, Division of Chemical Education, Journal of Chemical Education, March 2008(3), Volume 85, ISSN-0021-9584, 404-407, doi : $10.1021 / \mathrm{ed} 085 \mathrm{p} 404$.

[2] Edith A. Turi. Thermal Characterization of Polymeric Materials, ISBN: 978-0-12-703780-6, Academic Press: 1981.

[3] Thermal Characterization of Polymers, Analyzing \& Testing, Application notes, NETZSCH Handbook.

[4] Michael E. Brown. Introduction to Thermal Analysis Techniques and Applications, ISBN: 0-306-48404-8, Kluwer Academic Publishers, New York: 2004

[5] Dr. Gabriele Kaiser, Differential Scanning Calorimetry, Second Corrected edition, ISBN: 978-3-9821959-0-2, NETZSCH Handbook.

[6] G. W. H. Hohne, W. F. Hemminger H, J. Flammersheim. Differential Scanning Calorimetry: an introduction for practitioners, ISBN: 978-3540-00467-7, Springer:2003

[7] D. Pavlov, Lead-Acid Batteries: Science and Technology: A Handbook of Lead-Acid Battery Technology and Its Influence on the Product, Second Edition, ISBN: 978-0-444-59552-2, Elsevier Publications; 2017.

[8] Adrian Saal, Tino Hagemann, Ulrich S. Schubert. Polymers for Battery Applications-Active Materials, Membranes, and Binders, Advanced Energy Materials, Volume 11 2021, 2001984.
[9] Yoshiomi Fujiwara, Lead-acid battery container, lead-acid battery using the same, and lead-acid battery casing, European Patent Office EP 2835845 A1, 2014.

[10] G. Pircheraghi, M. Nowrouzi, Sh. Nemati. Fabrication of polyethylene separator for lead-acid batteries from waste and recycled silica and investigation of its performance, Journal of Cleaner Production, 2020(250), 119535.

[11] Peram Shyamsundar Reddy, Lokesh. H, Kosaraju Sreenivas, K.S.N.Murthy, M. Jagadish. A Review on Pasting Fibers and their Thermochemical Characteristics for Lead-Acid Energy Storage Devices, IJSR, 2020(9): 1646-1652.

[12] Zhao Zhongge, PVC battery separation plate production method and PVC battery separation plate, CN105428570A,2014.

[13] S K Martha, B Hariprakash, S A Gaffoor, D C Trivedi, A K Shukla. A low-cost lead-acid battery with high specific-energy, Journal of Chemical Sciences, February 2006;118(1): 93-98.

[14] Sudip Ray, Ralph P. Cooney, Thermal Degradation of Polymer and Polymer Composites, Chapter 9, Handbook of Environmental Degradation of Materials 2018(3): 185-206.

[15] Zhiming Gao, Tsuyoshi Kaneko, Iwao Amasaki, Masahiro Nakada. A kinetic study of thermal degradation of Polypropylene. Polymer Degradation and Stability, 2003;(80): 269-274.

[16] Mehrdad Seifali Abbas-Abadi. The effect of process and structural parameters on the stability, thermo-mechanical and thermal degradation of polymers with hydrocarbon skeleton containing PE, PP, PS, PVC, NR, PBR and SBR, Journal of Thermal Analysis and Calorimetry, 2021(143): 2867-2882.

[17] L N Shafigullin, N V Romanova, I F Gumerov, A T Gabrakhmanov, D R Sarimov. Thermal properties of Polypropylene and Polyethylene blends, IOP Conf. Series: Materials Science and Engineering, 412 012070, 2018.

[18] Eduard Piiroja, Helle Lippmaa. Thermal Degradation of Polyethylene, Macromolecular Symposia, 1989;27: 305-309.

[19] P. Bhandare, B. Lee, K. Krishnan. Study of Pyrolysis and Incineration of Disposable Plastics Using Combined TG/FT-IR Technique, Journal of Thermal Analysis, 1997;49: 361-366.

[20] B.J.Holland, J.N.Hay. The Thermal Degradation of PET and Analogous Polyesters Measured by Thermal Analysis - Fourier Transform Infrared Spectroscopy, Polymer, 2002;43: 1835-1847.

[21] Herbert A. Pohl, The Thermal Degradation of Polyesters, Journal of the American Chemical Society, 1951;73: 5660-5661.

[22] Yannick Soudais, Ludivine Moga, Jaroslav Blazek, Florent Lemort. Coupled DTA-TGA-FT-IR investigation of pyrolytic decomposition of EVA, PVC and cellulose, Journal of Analytical and Applied Pyrolysis, January 2007;78: 46-57.

[23] Jie Yu, Lushi Sun, Chuan Ma, Yu Qiao, Hong Yao. Thermal degradation of PVC: A review, Waste Management, February 2016;48 300-314

[24] B.E Tiganisa, L.S Burna, P Davisa, A.J Hill. Thermal degradation of acrylonitrile-butadiene-styrene (ABS) blends. Polymer Degradation and Stability, June 2002, 76;3:425-434.

[25] H. Polli, L. A. M. Pontes, A. S. Araujo, Joana M. F. Barros, V. J. Fernandes Jr. Degradation Behavior and Kinetic Study of ABS Polymer, Journal of Thermal Analysis and Calorimetry, 2009;95: 131134. 